\title{
Positron emission tomography in patients with psychogenic non-epileptic seizures
}

This article was published in the following Dove Press journal:

Neuropsychiatric Disease and Treatment

5 April 2016

Number of times this article has been viewed

\author{
Aileen McGonigal ${ }^{1-3}$ \\ Marie Arthuis ${ }^{3}$ \\ Jean-Arthur Micoulaud- \\ Franchi ${ }^{4,5}$ \\ Fabrice Bartolomei ${ }^{1-3}$ \\ Eric Guedj ${ }^{6-8}$
}

'Institut de Neurosciences des Systèmes, INSERM UMR II 06, Marseille, France; ${ }^{2}$ Aix Marseille University, Faculty of Medicine, Marseille, France; ${ }^{3}$ Clinical

Neurophysiology Department, Timone Hospital, Marseille,

France; ${ }^{4}$ Department of Functional Investigation of the Nervous System, Sleep Clinic, Bordeaux University Hospital, Bordeaux, France; ${ }^{5}$ USR CNRS 34I3, University of Bordeaux, France; ${ }^{6}$ Biophysics and Nuclear Medicine Department, Timone Hospital, Marseille, France; ${ }^{7} \mathrm{Aix}$ Marseille University, CERIMED, Marseille, France; ${ }^{8} \mathrm{Aix}-$ Marseille University, CNRS, UMR7289, INT, Marseille, France
Correspondence: Aileen McGonigal INSERM UI I06 Institut de

Neurosciences des Systèmes, Service de Neurophysiologie Clinique CHU Timone, Rue Saint Pierre, 13385 Marseille Cedex 5, France

Tel +3349l 385540

Email aileen.mcgonigal@univ-amu.fr

\section{Dear editor}

We have read with interest the recent review entitled "Uncovering the etiology of conversion disorder: insights from functional neuroimaging" by Maryam Ejareh dar and Richard AA Kanaan, ${ }^{1}$ published in Neuropsychiatric Disease and Treatment. Our paper on resting state brain metabolism measured by positron emission tomography (PET) was included and discussed. ${ }^{2}$ We were most surprised to see that the authors of the review seem to have misunderstood the findings of our study, which concerned patients with psychogenic non-epileptic seizures (PNES). The authors state that the 16 patients included in our study "were later found to have PNES with comorbid epilepsy". This is incorrect, since our study included only patients with PNES in whom comorbid epilepsy was excluded. This crucial point is indeed detailed in the Methods section of our article and clearly stated in the abstract: "in all patients, the diagnosis was subsequently confirmed to be PNES with no coexisting epilepsy." It is thus on the basis of incorrect understanding of our results that Drs Ejareh dar and Kanaan discuss the possible significance of hypometabolism in the anterior cingulate region described in our paper, and erroneously suggest that interpretation of PET findings is complicated by coexistent epilepsy, which was not in fact the case.

We certainly agree with the authors regarding the importance of reviewing the literature on this complex subject, and the need for further studies with more rigorous methodology. However a basic step is of course to read in detail the existing works and avoid dissemination of misinformation. Given the high standards of your journal and its interest in advancing knowledge in the field of neuropsychiatry, we would expect that this error be corrected in print, to avoid confusion.

\section{Disclosure}

The authors report no conflicts of interest in this communication.

\section{References}

1. Ejareh dar M, Kanaan RA. Uncovering the etiology of conversion disorder: insights from functional neuroimaging. Neuropsychiatr Dis Treat. 2016;12:143.

2. Arthuis M, Micoulaud-Franchi J, Bartolomei F, McGonigal A, Guedj E. Resting cortical PET metabolic changes in psychogenic non-epileptic seizures (PNES). J Neurol Neurosurg Psychiatry. 2014; 86(10):1106-1112. 


\section{Authors' response}

Maryam Ejareh dar

Richard AA Kanaan

Department of Psychiatry, University of Melbourne, Austin Health, Melbourne, NSW, Australia

\section{Dear editor}

We have read the concerns expressed by McGonigal et al, which appear to be justified. Our misreading of this text is inexplicable and we have provided the journal with a Corrigendum to correct this.

\section{Disclosure}

The authors report no conflicts of interest in this communication.

Dove Medical Press encourages responsible, free and frank academic debate. The content of the Neuropsychiatric Disease and Treatment 'letters to the editor' section does not necessarily represent the views of Dove Medical Press, its officers, agents, employees, related entities or the Neuropsychiatric Disease and Treatment editors. While all reasonable steps have been taken to confirm the content of each letter, Dove Medical Press accepts no liability in respect of the content of any letter, nor is it responsible for the content and accuracy of any letter to the editor.

\section{Publish your work in this journal}

Neuropsychiatric Disease and Treatment is an international, peerreviewed journal of clinical therapeutics and pharmacology focusing on concise rapid reporting of clinical or pre-clinical studies on a range of neuropsychiatric and neurological disorders. This journal is indexed on PubMed Central, the 'PsycINFO' database and CAS, and is the official journal of The International Neuropsychiatric Association (INA). The manuscript management system is completely online and includes a very quick and fair peer-review system, which is all easy to use. Visit http://www.dovepress.com/testimonials.php to read real quotes from published authors. 